Check for updates

Cite this: RSC Adv., 2017, 7, 49159

\title{
Preparation of a graphene/silver hybrid membrane as a new nanofiltration membrane $\uparrow$
}

\author{
Gui-fei Liu, (D) a Lin-jun Huang, ${ }^{* a}$ Yan-xin Wang, ${ }^{a}$ Jian-guo Tang, ${ }^{\text {*a }}$ Yao Wang, ${ }^{a}$ \\ Meng-meng Cheng, (DD a Yang Zhang, ${ }^{a}$ Matt J. Kipper, (D) ${ }^{\mathrm{b}}$ Laurence A. Belfiore ${ }^{\mathrm{b}}$ \\ and Wickramasinghe S. Ranil ${ }^{\mathrm{C}}$
}

In this study, we describe the preparation, characterization, water flux and rejection performance of a composite membrane formed from reduced graphene oxide (RGO) and silver nanoparticles (AgNP) via a rapid thermal reduction method. The nanocomposite is characterized by transmission electron microscopy (TEM), UV-visible spectroscopy (UV-vis), X-ray diffraction (XRD), scanning electron microscopy (SEM), field emission scanning electron microscopy (FESEM), and Fourier transform infrared spectroscopy (FTIR). The average diameter of the Ag nanoparticles is around $20-40 \mathrm{~nm}$. The RGO membranes and RGO-AgNP composite membranes were prepared by vacuum filtration of RGO-AgNPs dispersions through mixed cellulose filter membranes. We evaluated the water separation performance of the membranes, including water flux and rejection rate. The water flux is not only related to the concentration of silver particles and to the volume of solution used. High water flux and high rates of rejection of rhodamine B (85-99.9\%) are achieved.

Received 18th July 2017

Accepted 16th October 2017

DOI: $10.1039 / c 7 r a 07904 d$

rsc.li/rsc-advances such as filtration, separation, water desalination, biomimetic selective mass transport, energy storage and energy conversion. ${ }^{8-12}$ Graphene oxide (GO) as an oxygenated derivative of graphene. This hydrophilic layered carbon material, has also received a great deal of attention amongst researchers because it is light-weight, has a large specific surface area, is readily availability in bulk quantities, is inexpensive top prepare, has good water-dispersibility, and is readily functionalized by chemical reaction.

The two-dimensional structure and tunable physicochemical, properties of GO offer an opportunity to make a fundamentally new class of sieving membranes by stacking GO nanosheets. GO membranes have been prepared by vacuum filtration, ${ }^{\mathbf{1 2}-15}$ layerby-layer assembly, ${ }^{16-18}$ spray-coating, ${ }^{19}$ or spin-coating. ${ }^{20,21}$ Graphene-based films have two-dimensional nanochannels between restacked sheets, which create tortuous paths through hydrophobic nonoxidized material. This enables high water permeability through hydrophilic oxidized regions, and selective rejection of hydrophobic substances.

In the work by Nair et al., ${ }^{\mathbf{1 0}} \mathrm{GO}$ membranes fabricated via spin-coating had unique mass-transport properties favorable for the design of graphene-based membranes for filtration and separation applications. By tuning the physicochemical properties of the nanopores and the layer number of graphene membranes, the desired selectivity toward various gases and liquids and the ideal transmembrane fluxes can be generally obtained. ${ }^{22}$ Small spacing between GO nanosheets could be obtained by partially reducing GO to decrease the size of hydrated functional groups or by covalently bonding the stacked
Institute of Hybrid Materials, National Center of International Research for Materials Technology, National Base of International Science \& Technology Cooperation, College of Materials Science and Engineering, Qingdao University, Qingdao 266071, P. R. China.E-mail: newboy66@126.com; tang@qdu.edu.cn; Fax +86532 85951519; Tel: +8653285951961

${ }^{b}$ Department of Chemical and Biological Engineering, Colorado State University, Fort Collins, CO 80523, USA

${ }^{c}$ Ralph E. Martin Department of Chemical and Engineering, University of Arkansas, Fayetteville, AR 72703, USA

$\dagger$ Electronic supplementary information (ESI) available. See DOI: 10.1039/c7ra07904d 
GO nanosheets with small molecules to overcome the hydration force. In contrast, an enlarged GO spacing can be conveniently achieved by inserting soft polymer chains (e.g., polyelectrolytes) between GO nanosheets. Even larger-sized nanoparticles or nanofibers are also used as spacers, resulting in GO membranes ideal for applications in water purification, wastewater reuse, and pharmaceutical and fuel separation. ${ }^{23}$ Noble metal nanoparticles have attracted interest a wide range of applications due to their unique physicochemical properties. ${ }^{24-28}$

In this paper, in order to achieve an enlarged GO spacing, we added silver nanoparticles to GO for increasing the distance between layers, and then reduced the GO to RGO to obtain RGO-AgNP composites. The RGO-AgNP composite membranes were prepared by vacuum filtration. For comparison, we also prepared RGO and formed RGO membranes. We investigated water flux and rejection performance of the RGO membrane and the RGO-AgNPs composite membranes prepared with varying concentration of silver nanoparticles.

\section{Experimental section}

\subsection{Materials}

The chemicals, including sulfuric acid $\left(\mathrm{H}_{2} \mathrm{SO}_{4}, 98.0 \%\right)$, potassium permanganate $\left(\mathrm{KMnO}_{4}, 99 \%\right)$, phosphorus pentoxide $\left(\mathrm{P}_{2} \mathrm{O}_{5}\right)$, graphite, hydrogen peroxide $\left(\mathrm{H}_{2} \mathrm{O}_{2}, 30 \%\right)$, hydrochloric acid $(\mathrm{HCl}, 37 \%)$, silver nitrate $\left(\mathrm{AgNO}_{3}\right)$, sodium citrate and sodium borohydride. The above chemicals were analytical grade and provided by Beijing Chemical Factory.

\subsection{Preparation and of GO nanosheets and RGO-AgNPs composite}

Graphene oxide nanosheets were synthesized from natural graphite powder by the modified Hummers' method. ${ }^{29}$ The RGO nanosheets were reduced from the GO directly. The RGO-AgNPs composites were produced via directly reducing $\mathrm{AgNO}_{3}$ on GO nanosheets. The GO was then reduced to graphene. The reaction process of GO nanosheets and RGO-AgNP composite as shown in Fig. 1.

\subsection{Fabrication of RGO and RGO-AgNPs composite membrane}

The RGO membranes and RGO-AgNP composite membranes were prepared by vacuum filtration as described in our previous

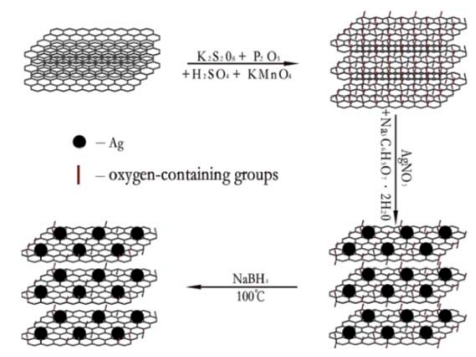

Fig. 1 The reaction process of GO nanosheets and RGO-AgNPs composite. studies. ${ }^{\mathbf{1 2}-15}$ The obtained dispersion (RGO and RGO-AgNP composite) was filtered through a $0.22 \mu$ mixed cellulose membrane ( $\Phi 50 \mathrm{~mm}$, Shanghai Xingya purifying material factory) to produce a membrane. The thickness of the RGO and RGO-AgNP membranes can be readily controlled by changing the volume of the RGO-AgNP composite solution filtered.

\subsection{Characterization}

The GO nanosheets, RGO nanosheets and RGO-AgNPs composites were characterized by transmission electron microscopy (TEM, JEOL 2011), UV-visible spectroscopy (UV-vis, Lambda 750), X-ray diffraction (XRD, D8 Advance), scanning electron microscopy (SEM, JEOL 6460), field emission scanning electron microscopy (FESEM, JSM-7500F), and Fourier transform infrared spectroscopy (FTIR, MAGNA-IR 550).

\subsection{Membrane flux and rejection tests}

The membranes were prepared by vacuum filtration of dispersions (RGO and RGO-AgNP composite) through mixed cellulose filter membranes.

The rejection performance of the membrane was examined using rhodamine $\mathrm{B}(\mathrm{RhB})$, a typical stable dyestuff, organic pollutants. The rejection rate was calculated as the \% change in solution concentration. The rejection rate $R$, using the following equations:

$$
R=\frac{F-P}{F} \times 100
$$

where $F$ is the absorbance of the $\mathrm{RhB}$ flowing into the membrane, $P$ is the absorbance of the RhB passing through the membrane.

\section{Result and discussion}

\subsection{SEM analysis}

Fig. 2(a) is a photograph of a RGO-AgNPs composite membrane. Fig. 2(b) show SEM images of the cross section of the as-obtained RGO-AgNPs composites membrane, which displays a wrinkled surface and a well-packed layered lamellar structure. FESEM analysis was used to investigate the surface morphology of the RGO-AgNPs composite membrane. Fig. 2(c and d) show FESEM images of the surface and the cross section of the RGO-AgNPs composite membrane, respectively. The FESEM images of the cross section of RGO-AgNPs composite membrane display a wrinkled surface and stacked lamellar structure, with some white spots between the layers as spacers. The top surface of the FESEM images of the RGO-AgNPs composite membrane appears as a dense surface with AgNPs (white spots), homogeneously spread on the surface of the membrane (Fig. 2(c)). The average diameter of the $\mathrm{Ag}$ nanoparticles is around 20-40 nm (Fig. 2(c)) and corroborating the TEM images.

\subsection{TEM analysis}

To further characterize the composite morphology more clearly, GO and RGO-AgNP composites were characterized by TEM. Representative TEM micrographs of the GO and RGO-AgNP 

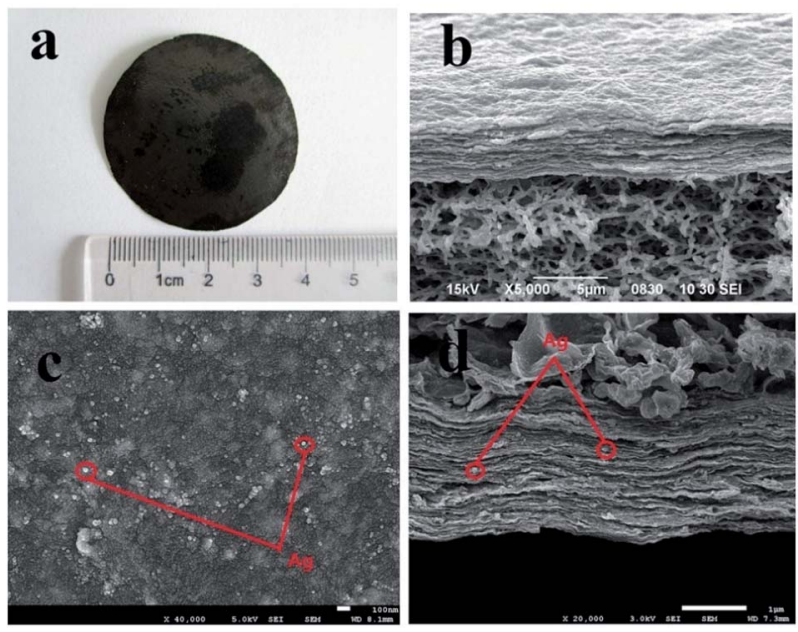

Fig. 2 Photographe (a), SEM images of (b) the cross section of an RGO-AgNP composite membrane (the top). FESEM images of (c) the surface and (d) the cross section of a RGO-AgNP composite membrane.

composite are shown in Fig. 3. Fig. 3(a) shows a TEM images of GO, with thin sheet-like morphology and sheets with wrinkled surfaces and folding at the edges were clearly visible. Fig. 3(b-d) show TEMs of RGO-AgNP composites with different mass ratios of $\mathrm{AgNO}_{3}$ to GO. A large number of $\mathrm{Ag}$ nanoparticles are nanometer sized and are homogeneously dispersed on the RGO sheets. The average diameter of the $\mathrm{Ag}$ nanoparticles is around 20-40 $\mathrm{nm}$. Most of the $\mathrm{Ag}$ nanoparticles fall in the size range from $20 \mathrm{~nm}$ to $30 \mathrm{~nm}$.
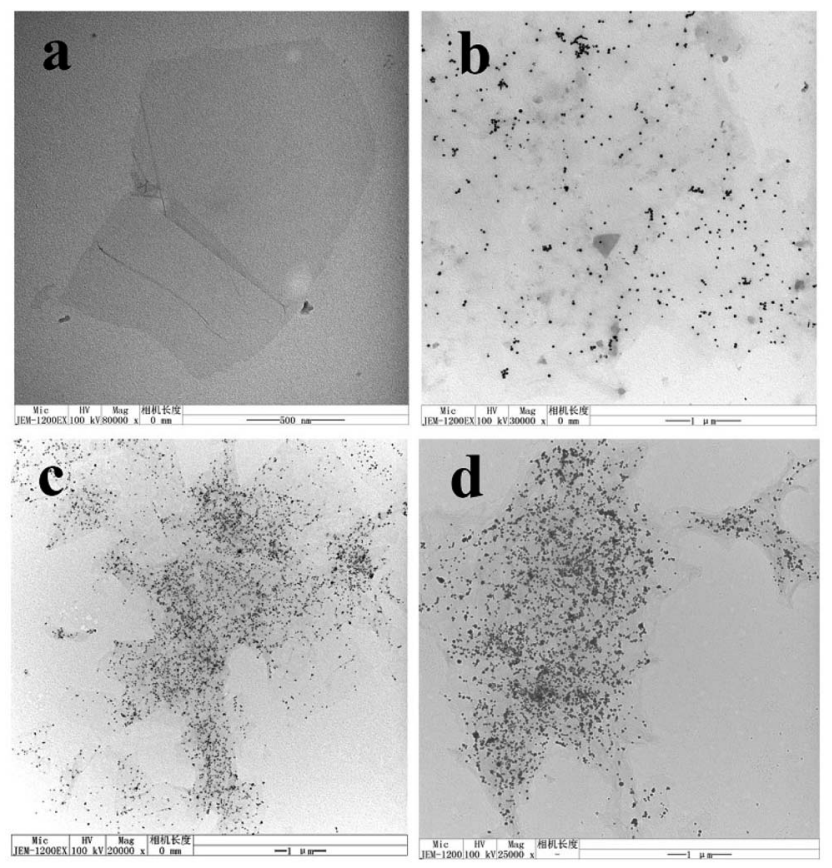

Fig. 3 TEM images of (a) GO, and RGO-AgNP composites with different mass ratios of $\mathrm{AgNO}_{3}$ to $\mathrm{GO}$, (b) for $1: 1$, (c) for $1: 2$ and (d) for $1: 3$, respectively.

\subsection{UV-visible spectroscopy analysis}

The formation of AgNPs on GO sheets was primarily confirmed by the UV-vis absorption spectroscopy (Fig. 4(a)). UV-vis absorption spectra were recorded of GO, RGO, and RGOAgNPs composites. GO has two absorption bands at $230 \mathrm{~nm}$ and $304 \mathrm{~nm}$ due to the excitation of the $\pi-\pi^{*}$ transition of aromatic $\mathrm{C}-\mathrm{C}$ and the $\mathrm{n}-\pi$ transition of $\mathrm{C}=\mathrm{O},{ }^{30}$ respectively. RGO dispersed in water solution has an absorption peak around $263.7 \mathrm{~nm}$ due to the incomplete reduction of GO. The dispersed RGO-Ag composite showed two main absorption peaks at $264 \mathrm{~nm}$ and $410 \mathrm{~nm}$. The peak at $264 \mathrm{~nm}$ is due to the incomplete reduction of GO. The absorption peak at $410 \mathrm{~nm}$ is the surface plasmon band of the Ag nanoparticles, indicating the formation of $\mathrm{Ag}$ nanoparticles on the RGO nanosheets surface. $^{12}$
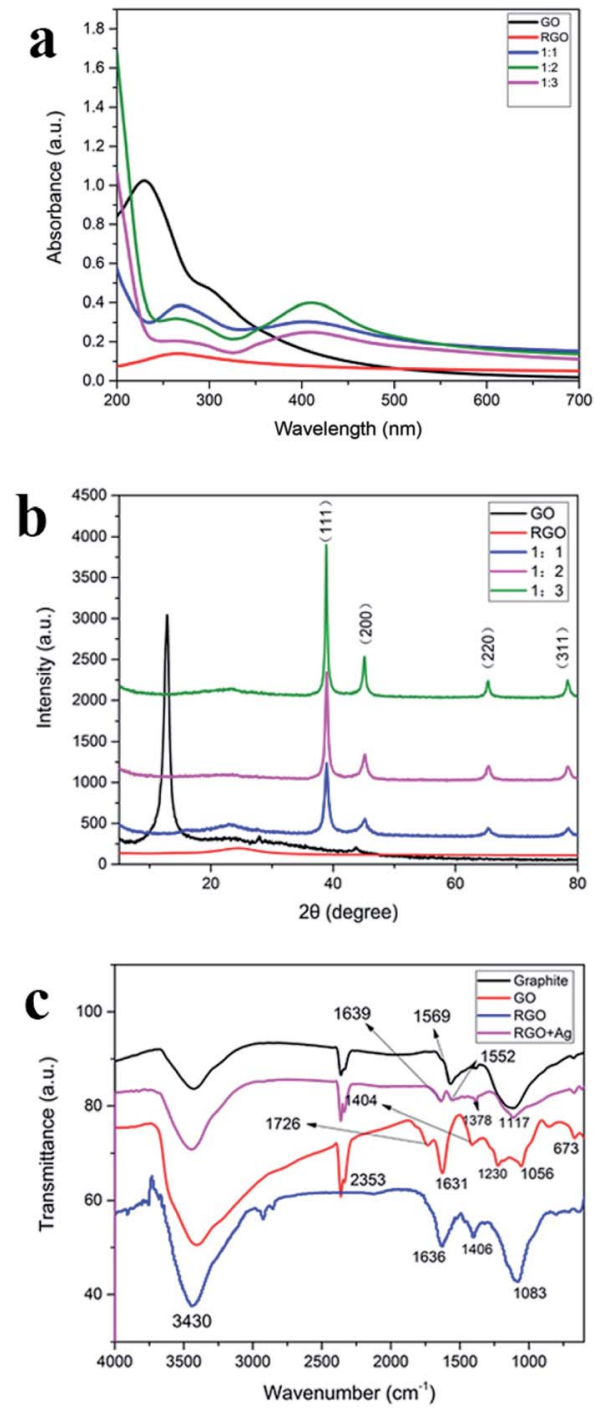

Fig. 4 (a) UV-vis absorption spectra of GO, RGO and RGO-AgNPs composite with different mass ratios of $\mathrm{AgNO}_{3}$ to $\mathrm{GO}$, (b) the X-ray diffraction (XRD) pattern of GO, RGO, and RGO-AgNP composite, and (c) FTIR spectra of graphite, GO and RGO-AgNPs composite. 


\subsection{XRD analysis}

Fig. 4(b) shows the X-ray diffraction (XRD) pattern of GO, RGO, and RGO/Ag. GO portrays its signature peak at $12.7^{\circ}$. The four diffraction peaks positioned at $38.8^{\circ}, 44.9^{\circ}, 65.2^{\circ}$, and $78.4^{\circ}$ for RGO-AgNPs composites are assigned to the (111), (200), (220), and (311) crystallographic planes of face-centered cubic (fcc) AgNPs, respectively. ${ }^{31}$ The peak at $12.7^{\circ}$ disappeared after the GO was decorated with silver nanoparticles. The X-ray diffraction patterns of the RGO-AgNPs composites prepared with different concentration of silver nitrate did not contain obvious diffraction peaks of GO. The explanation for this is that silver nanoparticles can be distributed on the surface of GO sheets to prevent the stacking of GO layers. With the increase of the concentration of AgNPs, the diffraction peak of silver nanoparticle is enhanced, especially the (111) crystallographic planes.

\subsection{FTIR analysis}

The FTIR spectra of graphite, GO, RGO and RGO-AgNPs composite are shown in Fig. 4(c). Graphite has three characteristic peaks and the absorption peaks are $\mathrm{C}=\mathrm{C}$ vibration $\left(1569 \mathrm{~cm}^{-1}\right)$, the peaks at $2359 \mathrm{~cm}^{-1}$ and $1113 \mathrm{~cm}^{-1}$ are the intrinsic absorption band of graphite material. The FTIR spectrum of GO indicates the presence of $\mathrm{C}=\mathrm{O}$ stretching vibration (1726 $\mathrm{cm}^{-1}$ ), unoxidized $\mathrm{C}=\mathrm{C}$ bonds in the carbon lattice $\left(1631 \mathrm{~cm}^{-1}\right)$, aromatic stretching vibrations of aromatic $\mathrm{C}=\mathrm{C}$ (1404 $\left.\mathrm{cm}^{-1}\right)$, C-O-C stretching $\left(1230 \mathrm{~cm}^{-1}\right), \mathrm{C}-\mathrm{O}$ stretching $\left(1056 \mathrm{~cm}^{-1}\right)$ and a broad $\mathrm{OH}$ stretching band $\left(3430 \mathrm{~cm}^{-1}\right)$. The oxygen containing functional group absorptions are much stronger in the GO spectrum compared to the graphene spectrum. The FTIR spectra of RGO, the OH stretching $\left(3430 \mathrm{~cm}^{-1}\right)$ is somewhat weakened, and the $\mathrm{C}=\mathrm{O}$ stretching vibration $\left(1726 \mathrm{~cm}^{-1}\right)$ and, $\mathrm{C}-\mathrm{O}-\mathrm{C}$ stretching $\left(1230 \mathrm{~cm}^{-1}\right)$ are almost completely eliminated, confirming the reduction of GO. Addition of AgNPs further reduces or eliminates peaks at $3430 \mathrm{~cm}^{-1}$, $1726 \mathrm{~cm}^{-1}$, and $1056 \mathrm{~cm}^{-1}$. This change indicates the interaction between $\mathrm{Ag}^{+}$and carboxylate groups on the edge of the GO sheets through the formation of a coordination bond or through simple electrostatic attraction and the reduction of $\mathrm{GO}^{32}$

\subsection{Water flux tests}

As mentioned above, the RGO-AgNPs composite membrane thickness can be readily controlled by changing the volume of the solution filtered. So, experiments were carried out on different samples and different volume of the solution filtered. As shown in Fig. 5(a), the water flux of the RGO-AgNPs composite membrane is greater than the flux for the RGO membrane. For membranes prepared using the same concentration of AgNPs, increasing the thickness of the membrane (by increasing the volume of sample filtered during membrane preparation) reduces the water flux. At the different concentration of AgNP and the same volume of the solution filtered, the greater higher concentrations of AgNPs used to prepare the membrane, result in greater water flux. In other words, the
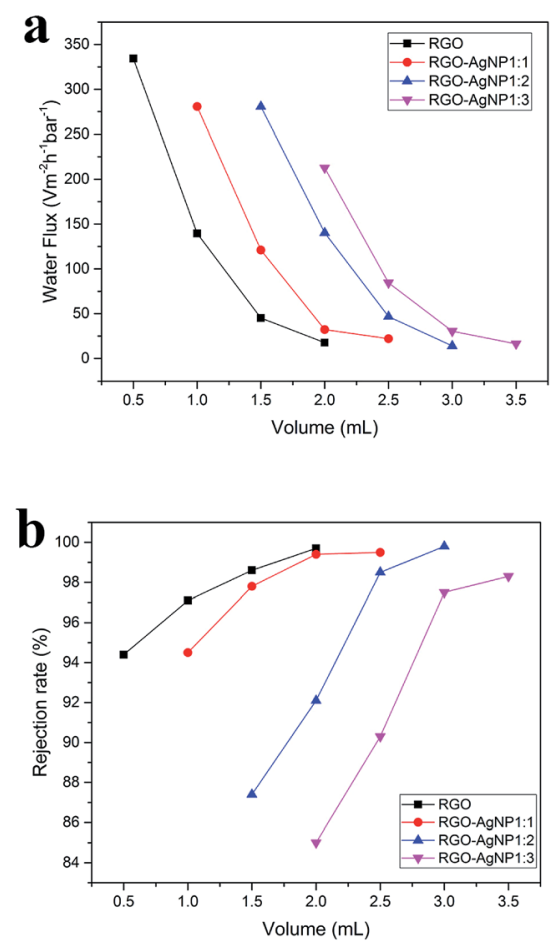

Fig. 5 (a) The water flux of membranes prepared using different volume of the RGO-AgNP composite solution with different mass ratios of $\mathrm{AgNO}_{3}$ to $\mathrm{GO}$, (b) the rejection rate for $\mathrm{RhB}$ of membranes prepared from different volume of the RGO-AgNP composite solution with different mass ratios of $\mathrm{AgNO}_{3}$ to $\mathrm{GO}$.

water flux is not only related to the concentration of silver particles, but also to the membrane thickness at the same concentration (Table 1).

\subsection{Rejection rate tests}

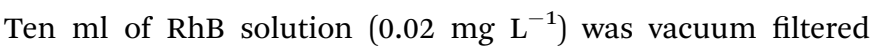
through the RGO-AgNPs composite membranes. The RhB concentration in the filtrate and the unfiltered solution were measured by UV-vis spectroscopy. The rejection rate was determined by comparing the concentration of $\mathrm{RhB}$ in the filtrate and the unfiltered solution. As seen in Fig. 5(b), the rates of rejection of RhB were in a range of $85-99.9 \%$. First, compared to the RGO membranes, the rejection is lower for the RGOAgNP composite membranes, and decreases as the AgNP

Table 1 The water flux of different volume of the RGO-AgNPs composite solution filtered with different mass ratios of $\mathrm{AgNO}_{3}$ to $\mathrm{GO}$

Water flux/L

$\mathrm{m}^{-2} \mathrm{~h}^{-1}$ bar $^{-1} \quad$ RGO $\quad 1: 1 \quad 1: 2 \quad 1: 3$

\begin{tabular}{lllll} 
& RGO & $1: 1$ & $1: 2$ & $1: 3$ \\
\hline $0.5 \mathrm{~mL}$ & 334.2 & - & - & -
\end{tabular}

$\begin{array}{lllll}1.0 \mathrm{~mL} & 139.6 & 280.7 & - & -\end{array}$

$\begin{array}{llll}1.5 \mathrm{~mL} & 45.2 & 121.0 & 280.7\end{array}$

$\begin{array}{lllll}2.0 \mathrm{~mL} & 17.7 & 32.3 & 140.3 & 212.7\end{array}$

$\begin{array}{lllll}2.5 \mathrm{~mL} & - & 22.1 & 46.8 & 84.5\end{array}$

$\begin{array}{lllll}3.0 \mathrm{~mL} & - & - & 14.0 & 30.5\end{array}$

$\begin{array}{llllll}3.5 \mathrm{~mL} & - & - & - & - & 16.3\end{array}$ 
Table 2 The rejection rate for $\mathrm{RhB}$ of different volume of the $\mathrm{RGO}-$ AgNPs composite solution filtered with different mass ratios of $\mathrm{AgNO}_{3}$ to $\mathrm{GO}$

\begin{tabular}{lllll}
\hline Rejection rate/\% & RGO & $1: 1$ & $1: 2$ & $1: 3$ \\
\hline $0.5 \mathrm{~mL}$ & 94.4 & - & - & - \\
$1.0 \mathrm{~mL}$ & 97.1 & 94.5 & - & - \\
$1.5 \mathrm{~mL}$ & 98.6 & 97.8 & 87.4 & - \\
$2.0 \mathrm{~mL}$ & 99.7 & 99.4 & 92.1 & 85.0 \\
$2.5 \mathrm{~mL}$ & - & 99.5 & 98.5 & 90.3 \\
$3.0 \mathrm{~mL}$ & - & - & 99.8 & 97.5 \\
$3.5 \mathrm{~mL}$ & - & - & - & 98.3 \\
\hline
\end{tabular}

concentration increases. At the same concentration of AgNP, the rejection rate decreases as the membrane thickness increases. The higher rate for RhB rejection can be attributed to one factor. RhB has a higher molecular weight, resulting in higher rejection by the size exclusion effect of the membrane (Table 2).

\subsection{Schematic discussion}

As mentioned above, due to the nanochannels between these restacked sheets, in the GO membrane, water permeates through a tortuous path, ${ }^{24}$ Fig. 6(a) shows a schematic of the permeation through GO laminates. The GO membranes have a void spacing of about $0.3 \mathrm{~nm}$ between GO nanosheets $\left(d_{1}\right)$. Incorporation of AgNPs increases the spacing. As we described earlier in the TEM and SEM images, the average size of the silver particles as spacer of GO is about $20 \mathrm{~nm}$, therefore the silver particles increased the spacing of GO to about $20 \mathrm{~nm}\left(d_{2}\right)$. Increasing the density of AgNP, results in further increase in the graphene sheet spacing, as illustrated in Fig. 6(c and d). We propose that, the AgNPs are stacked with each other on the graphene sheets, so the distance between the graphene sheets is increased by increasing the AgNP density. This result in increasing water flux and decreasing rejection rate for $\mathrm{RhB}$ as the weight of silver nanoparticles is increased, as observed in Fig. 7. As the article ${ }^{33}$ says, membranes separation applications obey a permeability/selectivity trade-off-highly permeable
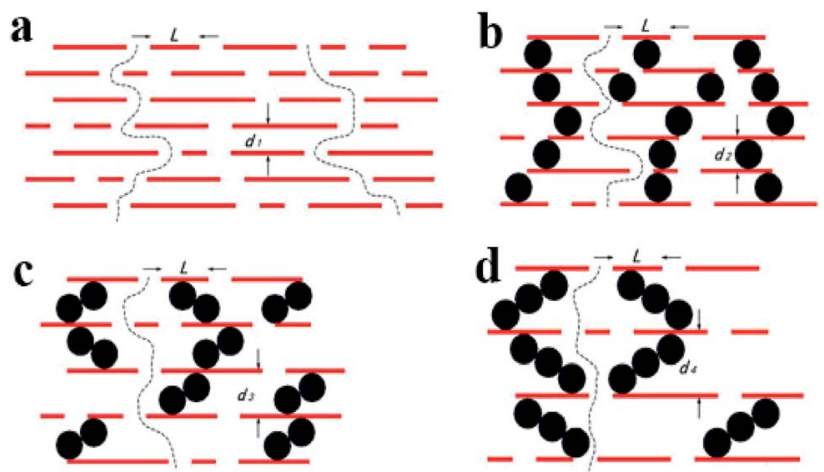

Fig. 6 Schematic diagram for the permeation through (a) GO and RGO-AgNP laminates with different mass ratios of $\mathrm{AgNO}_{3}$ to $\mathrm{GO}$, (b) for $1: 1$, (c) for $1: 2$, (d) for $1: 3$, respectively.
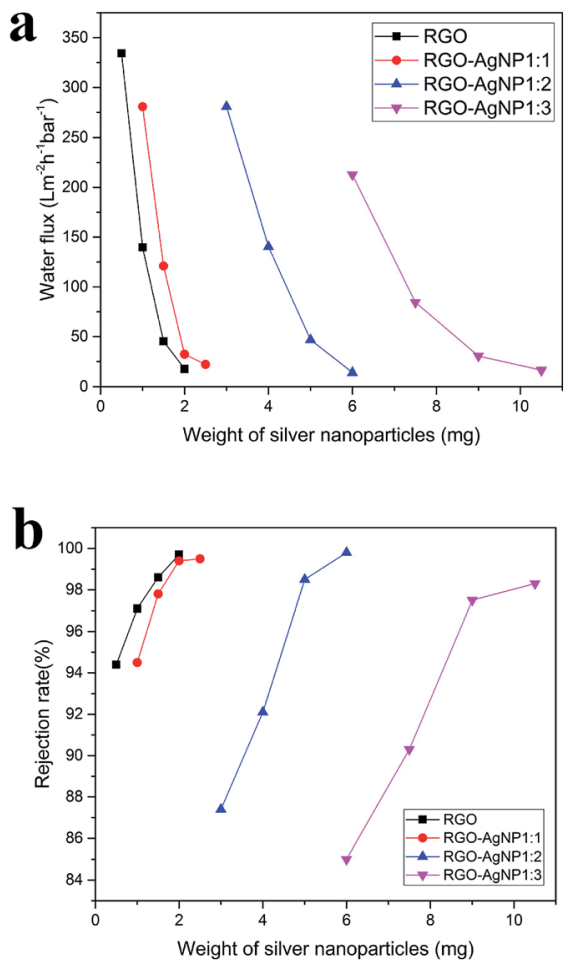

Fig. 7 ( $a$ and b) are the water flux and rejection rate for RhB after converting the volume of the RGO-AgNP composite solution to the weight of silver nanoparticles.

membranes have low selectivity and vice versa-largely due to broad distributions of free-volume elements (or pores in porous membranes) and nonspecific interactions between small solutes and polymers. Even though, we can choose the better combination performance through control the mass ratios of $\mathrm{AgNO}_{3}$ to $\mathrm{GO}$ in our work. The membrane with the mass ratios $1: 2$ of $\mathrm{AgNO}_{3}$ to $\mathrm{GO}$ has the best combination performance due to it's suitable distribution of silver nanoparticles. On the other hand, not all separation demands would benefits from membranes with ultrahigh permeability or selectivity. Increasing demand for energy-efficient gas and water separation, has stimulated substantial research aimed at overcoming the permeability/selectivity trade-off. And we will do some more research for this challenge in further.

In terms of water purification, most of the research ${ }^{17,34-36}$ is aimed at the graphene oxide membrane, and in these studies few metal-nanoparticles are used as spacers, so their water flux of the membrane are smaller than our work. For example, Han et $a l^{37}$ were prepared ultrathin graphene nanofiltration membranes. The pressure-driven separation performance of the resulting graphene laminates was evaluated on a dead end filtration device. The results showed that the as-prepared graphene nanofiltration membranes possess high water flux (21.8 $\left.\mathrm{L} \mathrm{m}^{-2} \mathrm{~h}^{-1} \mathrm{bar}^{-1}\right)$. $\mathrm{Hu}$ and $\mathrm{Mi}^{17}$ fabricated ultrathin (22-53 nm) GO membranes on a polydopamine-coated polysulfone support via a layer-by-layer self assembly technique with 1,3,5-benzenetricarbonyl trichloride (TMC) as crosslinkers. The water flux of the GO membranes were $80-276 \mathrm{~L} \mathrm{~m}^{-2} \mathrm{~h}^{-1} \mathrm{MPa}^{-1}$. 
By comparison, these results of the water flux are not as good as the results of our study. And on the other hand, most of the RGO/Ag composite membranes have been studied for their antibacterial activity due to the presence of silver particles. Sun et $a .^{\mathbf{1 2}}$ report an antibiofouling membrane onto cellulose acetate membrane. In this study, the presence of GO-AgNPs composite on the membrane exhibited a strong antibacterial activity, leading to an inactivation of $86 \%$ Escherichia coli after contacting with the membrane for $2 \mathrm{~h}$. Similar results were obtained by de Faria A. F. et al. ${ }^{38}$ This type of study may have great potential in developing high-performance antibiofouling membrane for membrane separation processes. Therefore, through the basic research of this experiment, we can further study the antimicrobial activity of this membrane in water treatment.

\section{Conclusions}

In this study, we developed the RGO-AgNP membranes. We have demonstrated that selective RGO-AgNP membranes can be prepared by a vacuum filtration method. These membranes enable water flow through two-dimensional nanochannels between these restacked sheets, and unwanted solutes can be rejected by size exclusion. In order to enlarge the spacing between the GO sheets, we added AgNP to GO. The water flux increases with increasing amounts of AgNP, and decreases with increased membrane thickness. By contrast, the rejection rate of RhB decreases with increased AgNP density, but increases with membrane thickness. The membrane with the mass ratios 1: 2 of $\mathrm{AgNO}_{3}$ to GO has the best combination performance due to its suitable distribution of silver nanoparticles, these properties indicate potential for water purification.

\section{Conflicts of interest}

There are no conflicts of interest to declare.

\section{Acknowledgements}

This work was supported by the (1) Natural Scientific Foundation of China (Grant no. 51641204, 51503112, 51373081), Natural Scientific Foundation of Shandong Province (Grant no. ZR2015EM008), Key Research and Development Plan of Shandong Province (Grant no. 2017GGX20112); (2) the Program for Introducing Talents of Discipline to Universities ("111" plan); (3) The National One-Thousand Foreign Expert Program (Grant No. WQ20123700111); (4) State Key Project of International Cooperation Research (2016YFE0110800); (5) the 1st level discipline program of Shandong Province of China.

\section{References}

1 A. M. Comerton, R. C. Andrews, D. M. Bagley and C. Hao, J. Membr. Sci., 2008, 313, 323-335.

2 T. Basile, A. Petrella, M. Petrella, G. Boghetich, V. Petruzzelli, S. Colasuonno and D. Petruzzelli, Ind. Eng. Chem. Res., 2011, 50, 8389-8401.
3 J. K. Holt, H. G. Park, Y. Wang, M. Stadermann, A. B. Artyukhin, C. P. Grigoropoulos, A. Noy and O. Bakajin, Science, 2006, 312, 1034-1037.

4 B. E. Logan and M. Elimelech, Nature, 2012, 488, 313-319.

5 D. Cohentanugi and J. C. Grossman, Nano Lett., 2012, 12, 3602.

6 J. Luo, L. J. Cote, V. C. Tung, A. T. Tan, P. E. Goins, J. Wu and J. Huang, J. Am. Chem. Soc., 2010, 132, 17667.

7 X. Li, X. Wang, L. Zhang, S. Lee and H. Dai, Science, 2008, 319, 1229.

8 L. Qiu, X. Zhang, W. Yang, Y. Wang, G. P. Simon and D. Li, Chem. Commun., 2011, 47, 5810-5812.

9 P. Sun, M. Zhu, K. Wang, M. Zhong, J. Wei, D. Wu, Z. Xu and H. Zhu, ACS Nano, 2013, 7, 428.

10 R. R. Nair, H. A. Wu, P. N. Jayaram, I. V. Grigorieva and A. K. Geim, Science, 2012, 335, 442.

11 H. Du, J. Li, J. Zhang, G. Su, X. Li and Y. Zhao, J. Phys. Chem. C, 2011, 115, 23261-23266.

12 X. F. Sun, J. Qin, P. F. Xia, B. B. Guo, C. M. Yang, C. Song and S. G. Wang, Chem. Eng. J., 2015, 281, 53-59.

13 J. Wang, P. Zhang, B. Liang, Y. Liu, T. Xu, L. Wang, B. Cao and K. Pan, ACS Appl. Mater. Interfaces, 2016, 8, 6211.

14 J. T. Robinson, M. Zalalutdinov, J. W. Baldwin, E. S. Snow, Z. Wei, P. Sheehan and B. H. Houston, Nano Lett., 2008, 8, 3441.

15 J. T. Robinson, F. K. Perkins, E. S. Snow, Z. Wei and P. E. Sheehan, Nano Lett., 2008, 8, 3137.

$16 \mathrm{M}$. Hu and B. Mi, J. Membr. Sci., 2014, 469, 80-87.

17 M. Hu and B. Mi, Environ. Sci. Technol., 2013, 47, 3715.

18 M. Hu, S. Zheng and B. Mi, Environ. Sci. Technol., 2016, 50, 685.

19 V. H. Pham, T. V. Cuong, S. H. Hur, E. W. Shin, J. S. Kim, S. C. Jin and E. J. Kim, Carbon, 2010, 48, 1945-1951.

20 H. A. Becerril, J. Mao, Z. Liu, R. M. Stoltenberg, Z. Bao and Y. Chen, ACS Nano, 2008, 2, 463.

21 C. Gómez-Navarro, R. T. Weitz, A. M. Bittner, M. Scolari, A. Mews, M. Burghard and K. Kern, Nano Lett., 2007, 7, 3499. 22 P. Sun, K. Wang and H. Zhu, Adv. Mater., 2016, 28, 2287.

23 B. Mi, Science, 2014, 343, 740.

24 B. Lim, M. Jiang, P. H. C. Camargo, E. C. Cho, J. Tao, X. Lu, Y. Zhu and Y. Xia, Science, 2009, 324, 1302-1305.

25 S. Guo, S. Dong and E. Wang, Adv. Mater., 2010, 22, 12691272.

26 Z. Ji, X. Shen, X. Yue, Z. Hu, J. Yang, Y. Wang, L. Ma and K. Chen, J. Colloid Interface Sci., 2015, 459, 79.

27 N. I. Ikhsan, P. Rameshkumar, A. Pandikumar, S. M. Mehmood, N. M. Huang, K. S. Vijay and H. N. Lim, Talanta, 2015, 144, 908-914.

28 S. Dhibar and C. K. Das, J. Alloys Compd., 2015, 653, 486-497. 29 L. J. Huang, Y. X. Wang, J. G. Tang, Y. C. Zhao, G. F. Liu, Y. Wang, J. X. Liu, J. Q. Jiao, W. Wang and B. Jin, J. Alloys Compd., 2016, 694, 1140-1148.

30 T. T. Baby and S. Ramaprabhu, J. Mater. Chem., 2011, 21, 9702-9709.

31 J. Li and C. Y. Liu, Eur. J. Inorg. Chem., 2010, 2010, 12441248. 
32 Q. Bao, D. Zhang and P. Qi, J. Colloid Interface Sci., 2011, 360, 463.

33 H. B. Park, J. Kamcev, L. M. Robeson, M. Elimelech and B. D. Freeman, Science, 2017, 356, 6343.

34 H. Meng, S. Zheng and B. Mi, Environ. Sci. Technol., 2016, 50, 685.

35 Z. Jia, W. Shi, Y. Wang and J. Wang, Colloids Surf., A, 2016, 494, 101-107.
36 S. M. Fatemi, M. Arabieh and H. Sepehrian, Carbon Lett., 2015, 16, 183-191.

37 Y. Han, Z. Xu and C. Gao, Adv. Funct. Mater., 2013, 23, 36933700 .

38 A. F. de Faria, D. S. Martinez, S. M. Meira, A. C. de Moraes, A. Brandelli, A. G. Filho and O. L. Alves, Colloids Surf., B, 2014, 113, 115-124. 